\title{
The Global Sharing Practice and Mechanism of Subprime Mortgage Crisis
}

\author{
Lu Guan \\ School of Economics and Management, Changchun University of Science and Technology \\ 7989, Weixing Road, Changchun 130022, Jilin Province, China
}

Tel: 86-136-6440-9239Ｅ-mail:gluguan@gmail.com

Peng Wang

China UNICOM Group Co., LTD. Jilin Branch, China

Received: September 20, 2012

Accepted: October 14, 2012

Online Published: November 1, 2012

doi:10.5430/afr.v1n2p196

URL: http://dx.doi.org/10.5430/afr.v1n2p196

\begin{abstract}
In this essay, the author describes the global sharing practice of the subprime mortgage crisis at the very beginning. Then, with the basis of the global sharing practice, the author mainly studies the global sharing mechanism of the subprime mortgage crisis in perspectives of global economic growth, international trade, and international inflation. At last, the author analyzes the strategic options for world leading powers responding to the subprime mortgage crisis from the angles of trade protection and financial protection.
\end{abstract}

Keywords: Subprime crisis, Global sharing mechanism, Game

\section{A review of the global sharing of the subprime mortgage crisis}

The U.S. subprime mortgage crisis has lasted for several years, which forced a number of world well- known lending institutions, investment banks, and commercial banks to accept the bankruptcy because of the damages in capital flows on one hand. On the other hand, it caused the huge fluctuation of the stock market. The whole economic area was seriously hurt. Due to the emergence of the subprime mortgage crisis, the global capital flows inevitably change, the financial activities decline, and the financial supports for economic growth reduce, what triggered the financial risk, being a serious negative factor in economic operation. It is necessary to evaluate and neutralize the effects of the U.S. subprime mortgage crisis.

Because of the closer connections of the financial systems in the main developed economies, the subprime mortgage crisis caused greater strikes on Europe, Japan, and other developed markets. With the "Butterfly Effect" of the subprime mortgage crisis, the shadows start spreading. All fields in international financial markets, including the stock market, the bond market, the foreign exchange market, and the commodities market, faced serious fluctuations, causing the deflation of western credit market. A large number of mortgage institutions, especially the funds and investment banks associated with the U.S. subprime mortgage market, fell into troubles or faced bankruptcy. In the U.S. financial market, the complicated structures of financial derivatives and the confusing transaction structure resulted in the information asymmetry of investors, who failed to really grasp the pricing of products, making the subprime mortgage crisis more mystery. The too much pessimistic psychological expectations became overwhelming. The investors lost their confidence in the market.

Since the year 2008, the United States the United States has sharply cut the base rate repeatedly and the overnight call rate of commercial banks reached the lowest in three years, what was the most radical high-frequency and large-margin interest-rate cut policy during the 25 years. Under the circumstances of the insufficient liquidity caused by the subprime mortgage crisis, the stagnation of M\&A (Mergers and Acquisitions), and the significant rise of overnight call rate, the world major central banks agreed to take action together to inject huge amounts of money to the financial system. 


\section{The global sharing mechanism for the indirect costs of the subprime mortgage crisis}

\subsection{The subprime mortgage crisis affected the global economic growth}

The subprime mortgage crisis caused a global financial crisis spreading around quickly, producing profound effects on the real economy. The Euro-zone economy was in recession. Japan and the United States showed negative growth respectively in the second and the third quarter in 2008. The developing countries suffered either. The world economic growth has slowed down significantly. The World Economic Outlook released by the IMF (International Monetary Fund) on Nov. $6^{\text {th }}, 2008$ showed that in 2008 the world economy grew by only $3.7 \%$, being the lowest in recent five years and the growth rate in developed countries was only $1.4 \%$ and that in emerging markets and developing countries was $6.6 \%$.

In 2009, the subprime mortgage crisis caused more serious damages on world economic growth. After the World War II, a negative growth emerged firstly in 2009. The developed economies were badly affected by the international financial crisis. Especially, Japan and Euro-zone suffered the most, the annual economy in which respectively shrank by $5.4 \%$ and $4.2 \%$. China and India still maintained a growth of more than $5 \%$. The contribution rate of China to the world economy exceeded 50\%, but conditions in Brazil and Russia were not satisfactory. Although the emerging economies and developed economies were badly affected by the subprime mortgage crisis, the damages were quite different.

\subsection{The subprime mortgage crisis increased the global inflationary pressures}

The outbreak of the subprime mortgage crisis caused a price rise of international bulk commodity and enhanced the insufficiency of global liquidity, resulting in the world-wide implementation of loose monetary policy in global economies. These influences significantly made the existing inflation more serious. First of all, an important sign for the trend of global inflation is the international commodity price. During the subprime mortgage crisis, the U.S. financial authorizes continued to make the depreciation of dollar in order to stimulate the economy, which finally caused the madly increase of oil price, as well as the prices of biological energy and bulk commodities. Besides, the price expectations for commodities in the unstable financial market were continuously increasing. They are the most direct signs for inflation. Secondly, several reasons contributed to the problem of global excess liquidity. Firstly, with no external constraints for the U.S. dollar, as the most important global reserve currency, its supply increased by an accelerated rate. Secondly, the side effects of saving-market policies by different countries began to take effect. The banks injected amounts of capitals to the market to ease the cargo credit crunch but without effective ways to get the money back. Thirdly, due to the rise of emerging countries' capabilities of investment, particularly the investments from Asian central banks, hedge funds, etc. increase the pressures of excess liquidity. Finally, the potential tendency of implementing a loose global monetary policy enhanced the pressure of inflation. Governments focused on keeping the price stable and maintaining the economic growth, what were the key points of the monetary policies. The interests-rate-cutting of the Federal Reserve and the subprime mortgage crisis affected all economies in the world, what made the Governments more inclined to implement the loose monetary policy, which also greatly increased the global inflation pressures.

In the advanced economies, because the prices of energies could counteract the changes of labor costs, the overall inflation rate rose to $1.25 \%$ in 2010 from zero in 2009. In the emerging economies and the developing economies, the inflation rate rose to $6.25 \%$ in 2010 , among which some economies faced increasing economic upward pressure because of economic downturn and more capital inflows.

\subsection{Restrain the international trade development}

In 2009, the world economy fell into the first negative growth after the World War II and the international trade experienced the biggest fall in the post-Cold War. According to the data released by the International Monetary Fund, because of the subprime mortgage crisis the world's international trade shrank by $11.9 \%$ in 2009 , the imports of developed economies decreased by $13.7 \%$ and exports by $13.6 \%$, the imports of emerging economies decreased by $9.5 \%$ and exports by $7.2 \%$. In the process of the subprime mortgage crisis spreading risks and damages, the world economy was affected negatively. With the expectation for the slowdown of world economy, the long-term development of international trade was restrained. The capital shrank due to the inflation, which would significantly dampen the purchasing power of each country. Because the demand for imports became less, the exports would not able to achieve growth.

The trade inhibition effect spread over and affected the export-oriented countries and regions from imports and exports by the global production chain, generating a double impact on the global trade. Since the 1970s the United States has become the "world buyer". Meanwhile, because of the knock-on effect caused by the deepening 
international division of labor, the decreasing demand of the United States has produced greater negative impacts on the foreign trade of emerging economies, including China. For instance, China's total export growth fell sharply to $6.52 \%$ in February in 2008. In the European zone, the exports to the United States experienced an inevitable decline, while the export was one of main forces pulling the economic growth in European zone. In this context, China's exports to EU sharply dropped from 71\% in February 2007 to 1\% in February 2008.

Several different factors inhibited the international trade, e.g. the hindered financing, the greater trade settlement risk caused by the instability of exchanges. Besides, another important factor was the rise of trade protection forces. In the United States, the Government launched a series programs dealing with the economic difficulties during the crisis period, including the terms of "Buy American".

\section{The crisis-loss-sharing game between the great powers}

With the coming of the subprime mortgage crisis, the Governments must not only focus on the domestic market, but also pay attention to the trends and strategies of competitors. As the global economy fell into the recession, some countries, especially the strong capitalism powers, used international trade to suppress other countries' economies and take resources. They took the excuse of stabilizing world finance and tried to maintain the hegemony to real economies.

\subsection{The war of green}

The 2009 Summer Davos Forum took the "green economy" as the core topic. The 2010 Boao Forum for Asia choose the "green recovery" as the theme. That was the interpretation for the low-carbon economy in a new era. The international financial crisis exposed the weakness of export-oriented economy and the stresses for environmental resources, revealing that the extensive mode of economic growth was not sustainable. In a report of HSBC, the survey covered nearly $\$ 480$ billion green investment program of 20 countries in the world, but till the first half of 2009 , only $\$ 14$ billion were actually consumed by the green causes.

There is always an ongoing process of balancing interests between developed countries and developing countries. The United States and European Union even hope to abolish the Kyoto Protocol and rebuild a new binding agreement including developing countries, implementing the monorail system. However, developing countries think that developed countries cannot shirk its historical responsibility of global environmental issues caused by the emissions of a large number of greenhouse gas during their industrial development process. Therefore, they completely resist such proposals. Meanwhile, developing countries ask developed countries to provide financial and technological supports. Presently, considering the commitment of developed countries, the developed countries, as a whole, are still far from reaching the minimum target of $25 \%$ reduction by 2020 , while developing countries agree that a reasonable percentage for developed countries' emission reduction should be $40 \%$. At the climate conference, most of developed countries only discussed the size of capital investment vaguely but no specific promises to the contribution ratios of emission reduction or the obligations.

\subsection{Obama: Buy American}

The U.S. Congress examined the economic stimulus bill and passed the $\$ 8190$ billion of new economic stimulus bill. According to one of the provisions, all infrastructure projects must use the America-made steel products if the projects hope to get the financial support from the new economic stimulus bill. This provision was met with fierce criticism from European Union and Canada who are the important trading partners of the United States. The protectionist provision, i.e. "Buy American", was the focus. This provision restricted the import in order to protect the domestic industries of the United States, for which it was criticized inside and outside. Although the bill did not pass at last, voices of protectionists began to rise because of the fact that the exports were restricted by global economic recession and trade protectionism. In perspective of economics, the trade game is the most primary aspect of "superpower game". It is a huge strike on Chinese economy, in which the exports account for $37.57 \%$ of the GDP. This imbalance means that Chinese Government must continue to increase the investments in public engineering projects by previously accumulated exchange reserve and fiscal income in order to maintain the current economic growth. Since the "made in China" products entered the U.S. market, China has become the main reason for the U.S. trade deficit. The United States has begun to take action against China. During three consecutive years, the United States International Trade Commission respectively imposed 55\%, 45\%, and 35\% ad valorem special tariffs against Chinese passenger car and light truck tires.

With economic globalization, the WTO and the bilateral negotiation mechanism tend to be more perfect. There is minimum possibility of triggering the "trade war" among two or more trading powers. However, the trade friction is inevitable. The great power game is always the duel of wisdom and powers. The United States, as the No.1 economic 
power in the world, is still capable of imposing sanctions against any country or region. The emerging economies, i.e. China as a representative, are not strong enough to starting attacks. Actions stand for voices. The game in the process of world polarization is bound to the collision of different voices.

\subsection{The rise of emerging economies}

As the world economy falls in the great recession, the emerging economies contribute some positive signs to the world, even surrounding by the gloomy economy. In 2011, more than $50 \%$ of world economic growth is from the BRIC (Brazil, Russia, India, and China). The emerging economies have become the irreplaceable important strengths in the world economic arena.

In the "G20" Summit in France, the BRIC, as the new global powers and the new pattern in international political and economic system, fought for their "voices" as the partner. The World Bank and the IMF also agree that the emerging markets and countries should "take their shares they deserve", especially for China that possess two trillion U.S. dollars of foreign reserve, with higher GDP than Japan. The EU calls on countries to negotiate the reform of financial system program in the "G20" Summit in France and hopes to hold a new round of summit within 100 days after the Summit in France in order to make up practical reform program and build new regulatory orders. China is the typical representative of emerging economies. Both the EU and the United States compete for the Chinese market. The EU has always advocated to strengthen the global financial regulatory, so did China. Generally speaking, China has already achieved breakthrough progresses in the international economic arena.

\section{References}

Ahearne, Alan, Cline, William R., Lee, Kyung Tae, Park, Yang Chul, Pisani-Ferry Jean and Williamson, John. "Global Imbalances: Time for Action", Policy Brief, No. PB07-4, Peterson.

Bulow, J and Klemperer, P. (2009). Reorganising the banks: focus on the liabilities, not the assets [ R/ OL], [Online] Available: www.voxeu. org/ index.php?q= node/3320.

Ding, Chun. (2010). European economy under the strike of financial crisis: situations, causes, and prospects. Europe Studies, 12.

Douglas W. Diamond \& Raghuram Rajan. (2009). The credit crisis: conjectures about causes and remedies. NBER working papers No14739.

Jan Schildbach. (2010). Direct fiscal cost of the financial crisis, Deutsche Bank Research, May- 14.

Yu, Yongding. (2011). The global public credit crisis and the challenges in front of China during the post-crisis period. International Economic Review, 1. 